\title{
Imaging in Double Gall Bladder with Acute Cholecystitis-A Rare Entity
}

\author{
Praveen Kumar Vasanthraj, Rajoo Ramachandran, Kumaresh Athiyappan, \\ Anupama Chandrasekharan, Cunnigaiper Dhanasekaran Narayanan
}

Department of Radiology, Sri Ramachandra University, Chennai, India

Email: drrajoor@gmail.com

Received 28 April 2014; revised 26 May 2014; accepted 22 June 2014

Copyright (C) 2014 by authors and Scientific Research Publishing Inc.

This work is licensed under the Creative Commons Attribution International License (CC BY). http://creativecommons.org/licenses/by/4.0/

c) (7) Open Access

\begin{abstract}
Duplication of gall bladder is a rare congenital anomaly of the hepatobiliary system. It is a very important entity in clinical practice as preoperative diagnosis plays a significant role in the management and to avoid unnecessary bile duct injury during surgery. We report a case of duplicated gall bladder presenting as acute cholecystitis.
\end{abstract}

\section{Keywords}

Gall Bladder, Duplication, Cholecystitis

\section{Introduction}

Gall bladder (GB) duplication is a rare congenital anomaly of hepatobiliary system with a reported incidence of about 1 per 4000 autopsies [1]. Duplication of gall bladder and their varying anatomical positions are associated with an increased risk of complications including biliary leak after laparoscopic or open cholecystectomy [2]-[5].

\section{Case Presentation}

A 45 years old lady presented with complaints of abdomen pain for the past two days. It was colicky type pain, intermittent in nature and localized to the right hypochondrium. She also gave history of three episodes of vomiting which was non bilious, non blood stained and non foul smelling. No past history of jaundice and fever. On clinical examination there was tenderness in the right hypochondrium. Baseline blood investigation showed elevated total bilirubin $(1.5 \mathrm{mg} / \mathrm{dl})$, elevated direct bilirubin $(0.67 \mathrm{mg} / \mathrm{dl})$, elevated Serum glutamic oxaloacetic transaminase (SGOT-96 U/L) and Serum glutamic pyruvic transaminase (SGPT-243 U/L) levels. Transabdominal ultrasound (USG) revealed multiple calculi within the lumen of the gall bladder with wall thickening (Figure 1). In view of raised direct bilirubin levels and to rule out obstructive disease, magnetic resonance im- 
aging (MRI) abdomen was performed.

MRI abdomen on axial T2 single shot fast spin echo (SSFSE), axial and coronal T2 fast imaging employed steady state acquisition (FIESTA) (Figure 2) sequences revealed a distended gallbladder with diffuse wall thickening of $5 \mathrm{~mm}$. multiple small calculi were seen within the lumen. Minimal pericholecystic fluid was also seen.

A cystic structure measuring $3 \times 1.7 \mathrm{~cm}$ with a narrow duct was seen lateral to the second part of the duodenum which was seen communicating with the middle segment of the cystic duct of gallbladder mentioned before, suggestive of double gallbladder with a common cystic duct.

The common bile duct and the common hepatic duct were mildly dilated $(7 \mathrm{~mm})$ with gradual tapering at the
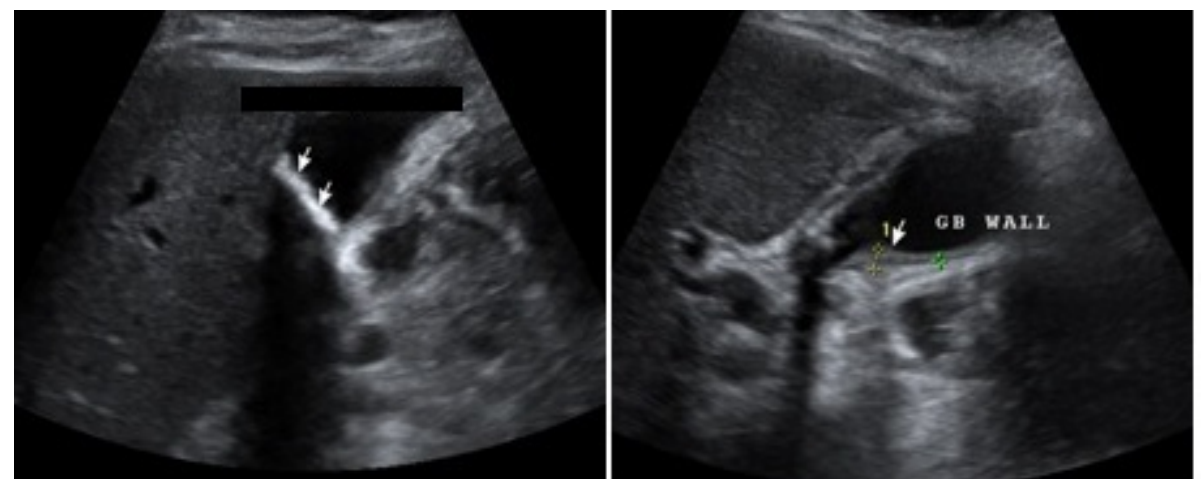

Figure 1. Transabdominal USG of the gall bladder shows multiple calculi (straight arrow) within the gall bladder with associated wall thickening.

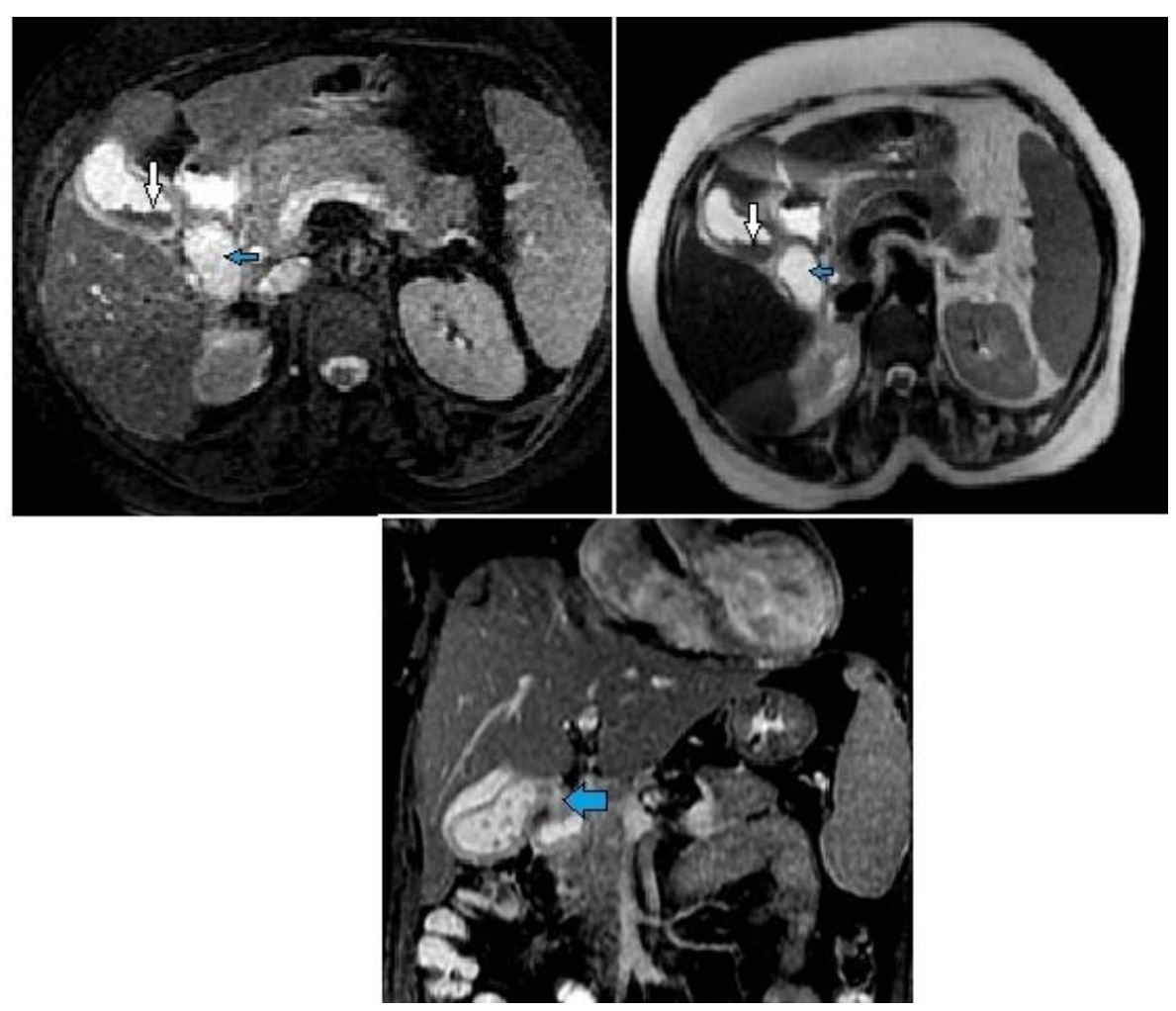

Figure 2. MRI of abdomen with Axial T2 FIESTA, T2 SSFSE and Coronal T2 FIESTA images showing two pear shaped structures in the gall bladder fossa suggestive of duplicated gall bladder. The laterally placed gall bladder shows thickened wall with sludge within (white arrow). The duplicated gall badder (blue arrow) is seen inferomedial to the primary gall bladder. On coronal imaging the common cystic duct is appreciated (thick blue arrow). 
distal end. No calculi seen. Mild prominence of the right and left intra hepatic ducts were seen.

Magnetic resonance cholangiopancreatography (MRCP) with 3D reconstruction was done which showed double gall bladder with a common cystic duct (Figure 3).

Following radiological suspicion of double gall bladder, Endoscopic retrograde cholangiopancreatography (ERCP) was performed which showed the presence of two separate pear shaped structures filling with contrast with a common cystic duct (Figure 4).

Subsequently the patient was taken up for surgery the following day. Laparoscopic Cholecystectomy was done and both the gallbladders were removed (Figure 5). The specimen was sent for pathological analysis which confirmed the diagnosis (Figure 6).

\section{Discussion}

Duplicated gallbladder is one of the rare anomalies of biliary system. Embryologically during fifth or sixth week of gestation, abnormal bifurcation of pars cystic results in the formation of double gall bladder [6]. Because of associated anatomical variations of cystic duct and hepatic artery, this congenital anomaly is important to know for the surgeons and imaging plays a vital role in preoperative workup.
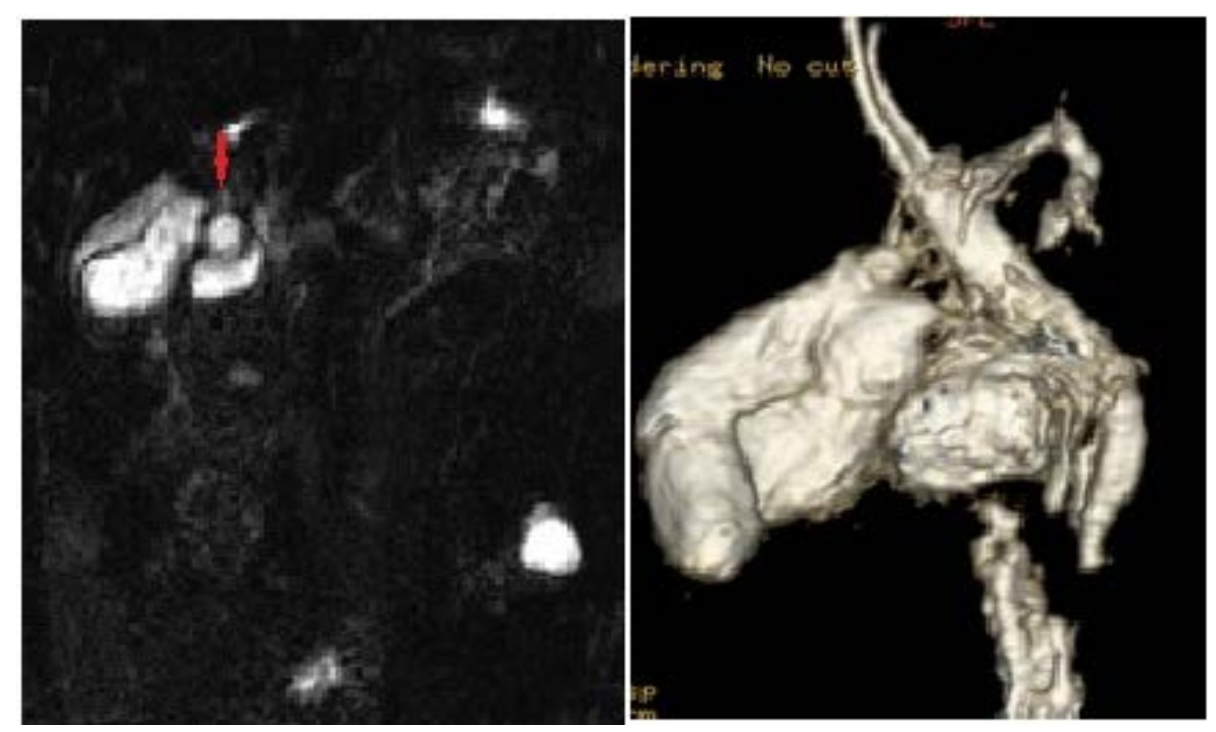

Figure 3. MRCP with 3D destruction shows double gall bladder with common cystic duct (red arrow). MRI and MRCP was performed on 1.5 T GE machine.

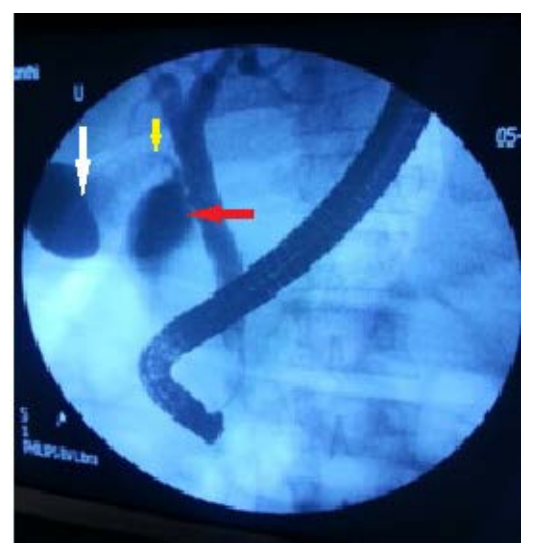

Figure 4. ERCP shows two pear shaped contrast filling structures in the gall bladder fossa suggestive of double gall bladder with a common cystic duct. The (white arrow) indicates the primary gall bladder. The (red arrow) indicates the duplicated gall bladder. The (yellow arrow) indicates the common cystic duct. 


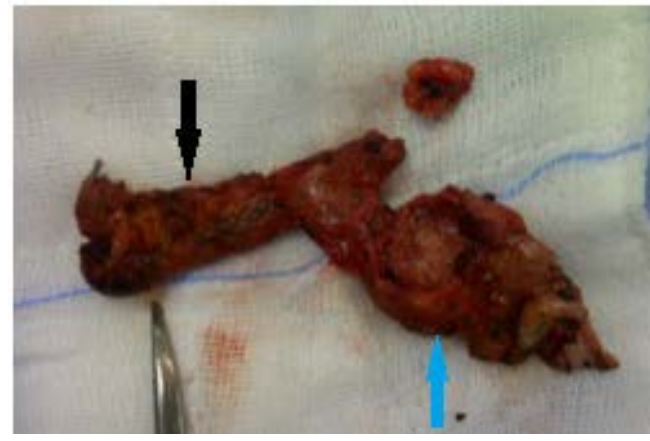

Figure 5. Immediate post cholecystectomy image showing two gall bladders with a common cystic duct. The (black arrow) shows the duplicated gall bladder and the (blue arrow) indicates the primary gall bladder with cholecystitis.

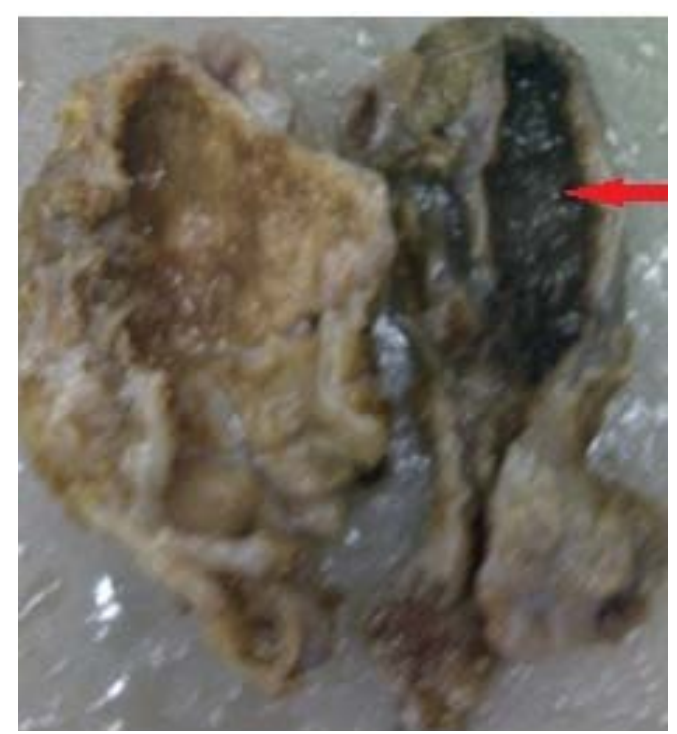

Figure 6. Pathological gross specimen showing double gall bladder. The primary gall bladder contains multiple calculi within (red arrow). The duplicated gall bladder is seen adjacent to it.

With first case noted as early as in $31 \mathrm{BC}$, the estimated incidence is one in every 4000 autopsies [7]. However the incidence of reported symptomatic cases is probably very low. There have been around 65 to 70 cases of gallbladder duplication in the literature. There are few incidences wherein patients with post-cholecystectomy status have presented with second attack of cholecystitis.

There are no specific symptoms or signs associated with multiple gallbladders; rarely there may be vague abdominal pain. The common pathologies that can occur in the second moiety include cholelithiasis, cholecystitis, cholecystocolic fistula, empyema, torsion, and carcinoma. Most duplicated gallbladders usually lie adjacent to each other and share a common peritoneal coat. Occasionally, one could be entirely intrahepatic or sub-hepatic. True gallbladder duplications show variations such as a common cystic duct and arterial supply or can have separate cystic ducts and blood supply [7]-[9].

In our case, two separate cystic ducts were seen which in turn joined to form a common distal cystic duct draining into the common bile duct. Intraoperatively three cystic arteries were noted.

Ultrasound, CT scan, MRCP, scintigraphy and oral cholecystography help in identifying GB anomalies but they do have their limitations and are not $100 \%$ sensitive in identifying biliary ductal anomalies. ERCP also acts as an adjunct procedure in establishing the diagnosis. 
USG is usually the first choice of investigation. The ultrasonographic differentials include gallbladder diverticulum, pericholecystic fluid collections, choledochal cysts, folded gallbladder, phrygian cap, and extrinsic fibrous bands across the gallbladder. Due to similar sonographic appearances the differentiation among double gallbladder, folded gallbladder and fibrous or vascular band may be difficult. If gallstones can be demonstrated to communicate with all parts of the gallbladder, a folded gallbladder is more likely. Gallstones may become sequestered in a compartmentalized part of the gallbladder, such as phrygian cap; in such instances, the morphology of the gallbladder should still maintains its oblong shape in contrast to two separate gall bladders in duplication.

Helical contrast enhanced CT abdomen (CECT) with positive oral contrast can be used to differentiate GB abnormalities from duodenal pathologies. However, it is seldom used due to poor visualization of intra hepatic biliary radicles (IHBR) and advanced techniques in MRI. CECT may be helpful in demonstrating other vascular anomalies associated with duplication [10].

MRCP, a noninvasive imaging technique has been found valid in evaluation of patients with suspected gall bladder anomalies and biliary system [11]. In our case MRCP revealed features of acute calculus cholecystitis in one gall bladder. It also demonstrated another pear shaped cystic structure within the GB fossa which had a thin linear tract joining the cystic duct of the gall bladder with features of acute calculus cholecystitis raising the suspicion of duplicated gall bladder.

Gallbladder duplication should be suspected when two cystic structures are present in the gallbladder fossa. A more specific sign of gallbladder duplication may be isolated contraction of the non diseased lobe with absent contraction of a diseased lobe. This finding may be useful for differentiating between double gallbladder and other forms of pericholecystic fluid collection. It may also suggest partial duplication of the cystic duct, since a patent cystic duct must be present for the non diseased lobe to contract.

Duplication of the gallbladder has also been detected by percutaneous transhepatic cholangiography, oral cholecystography and scintigraphy. But these procedures are not routinely used in patients with biliary disease.

ERCP is a useful adjunct but it may not be indicated in every case of cholelithiasis or cholecystitis. In our case ERCP showed two pear shaped structures filled with contrast through one common cystic duct. However ERCP will not always be able to demonstrate the duplicated GB, because of this there are chances that surgeon might miss the additional structure or presumed to be normal. This could account for the missed cases reported in the literature and in those who underwent a second operation for a diseased remnant gallbladder.

Per operative USG, cholecystography or cholangiography in suspected cases can help in identifying the additional structure.

The most widely accepted classification for double gallbladder is the Boyden's classification. The two main types of duplications are vesica fellea divisa (bilobed gallbladder) and vesica fellea duplex (true duplication), with two different cystic ducts. The true duplication is sub classified into $\mathrm{H}$ shaped type and $\mathrm{Y}$ shaped type. In $\mathrm{H}$ shaped type there are two separate gallbladders and their respective cystic ducts enter separately into the common bile duct. In Y shaped type, there are two gall bladders with two cystic ducts. The two cystic ducts unite to form a common channel before its termination into the common bile duct. In our case it was vesica fellea duplex with Y shaped type [12].

Previously reported literature clearly emphasizes the need for removal of accessory or duplicate gallbladders to prevent surgical complications and repeated explorations [13].

There has been emphasis on the need for open procedures to identify these anomalies in the past. In the present scenario, with the advent of newer imaging modalities and expertise, these rare anomalies can be diagnosed pre operatively and can be successfully treated by laparoscopy with minimal morbidity.

The possibility of a second gallbladder needs to be bore in mind in case of persisting symptoms after cholecystectomy. Sometimes even modern radiological techniques can sometimes fail to spot such abnormalities without a high index of suspicion [14]. Hence the focus should be on preoperative diagnosis of this variation as they can be easily missed at the time of surgery leading to persistent symptoms after surgery, intraoperative complications and often the need of performing repeated surgical procedures.

\section{Conclusion}

Duplicated gall bladder is a rare congenital anomaly, which requires a detailed preoperative imaging of biliary and the arterial anatomy to avoid unnecessary biliary injury. It is very important to be familiar with this rare ent- 
ity, so that it is not confused with other pathological conditions of the hepatobiliary system.

\section{Acknowledgements}

The author would like to thank mother, father, wife and friends for their moral support and patience.

\section{Competing Interest}

The author claims that there is no competing interest.

\section{Consent}

Consent approved by the patient.

\section{References}

[1] Boyden, E.A. (1926) The Accessory Gallbladder: An Embryological and Comparative Study of Aberrant Biliary Vesicles Occurring in Man and in Domestic Mammals. American Journal of Anatomy, 38, 177-231. http://dx.doi.org/10.1002/aja.1000380202

[2] Gigot, J.F., Van Beers, B., Goncette, L., et al. (1997) Laparoscopic Treatment of Gallbladder Duplication: A Plea for Removal of Both Gallbladders. Surgical Endoscopy, 11, 479-482. http://dx.doi.org/10.1007/s004649900396

[3] De Leeuw, Th.G., Verbeek, P.C.M., Rauws, E.A.J. and Gouma, D.J. (1995) A Double or Bilobar Gallbladder as a Cause of Severe Complications after (Laparoscopic) Cholecystectomy. Surgical Endoscopy, 9, 998-1000. http://dx.doi.org/10.1007/BF00188459

[4] Borghi, F., Giraudo, G., Geretto, P. and Ghezzo, L. (2008) Perforation of Missed Double Gallbladder after Primary Laparoscopic Cholecystectomy: Endoscopic and Laparoscopic Management. Journal of Laparoendoscopic \& Advanced Surgical Techniques, 18, 429-431. http://dx.doi.org/10.1089/lap.2007.0088

[5] Udelsman, R. and Sugarbaker, P.H. (1985) Congenital Duplication of the Gallbladder Associated with an Anomalous Right Hepatic Artery. American Journal of Surgery, 149, 812-815. http://dx.doi.org/10.1016/S0002-9610(85)80193-8

[6] Vijayaraghavan, R. and Belagavi, C.S. (2006) Double Gallbladder with Different Disease Entities: A Case Report. Journal of Minimal Access Surgery, 2, 23-26. http://dx.doi.org/10.4103/0972-9941.25673

[7] Garcia, J.C., Weber, A., Berry, F.S. and Tatz, B.T. (1993) Double Gallbladder Treated Successfully by Laparoscopy. Journal of Laparoendoscopic Surgery, 3, 153-155. http://dx.doi.org/10.1089/lps.1993.3.153

[8] Miyajima, N., Yamakawa, T., Varma, A., Uno, K., Ohtaki, S. and Kano, N. (1995) Experience with Laparoscopic Double Gallbladder Removal. Surgical Endoscopy, 9, 63-66. http://dx.doi.org/10.1007/BF00187889

[9] Horattas, M.C. (1998) Gallbladder Duplication and Laparoscopic Management. Journal of Laparoendoscopic \& Advanced Surgical Techniques, 8, 231-235. http://dx.doi.org/10.1089/lap.1998.8.231

[10] Ozgen, A., Akata, D., Arat, A., Demirkazik, F.B., Ozmen, M.N. and Akhan, O. (1999) Gallbladder Duplication: Imaging Findings and Differential Considerations. Abdominal Imaging, 24, 285-288. http://dx.doi.org/10.1007/s002619900496

[11] Mazziotti, S., Minutoli, F., Blandino, A., Vinci, S., Salamone, I. and Gaeta, M. (2001) Gallbladder Duplication: MR Cholangiography Demonstration. Abdominal Imaging, 26, 287-289. http://dx.doi.org/10.1007/s002610000157

[12] Lamah, M., Karanjia, N.D. and Dickson, G.H. (2001) Anatomical Variations of the Extra Hepatic Biliary Tree: Review of the World Literature. Clinical Anatomy, 14, 167-172. http://dx.doi.org/10.1002/ca.1028

[13] Goel, A., Srivastava, K.N. and Rana, A.K. (2003) Double Gallbladder-Laparoscopic Management. Surgical Laparoscopy Endoscopy \& Percutaneous Techniques, 13, 348-349. http://dx.doi.org/10.1097/00129689-200310000-00013

[14] Lefemine, V. and Lazim, T.R. (2009) Neuroma of a Double Gallbladder: A Case Report. Cases Journal, 2, 11. http://dx.doi.org/10.1186/1757-1626-2-11 


\section{Abbreviations}

CECT: Contrast Enhanced Computed Tomography

CT: Computed Tomography

FIESTA: T2 Fast Imaging Employed Steady State Acquisition

ERCP: Endoscopic Retrograde Cholangiopancreatography

GB: Gall Bladder

IHBR: Intra Hepatic Biliary Radicles

MRCP: Magnetic Resonance Cholangiopancreatography

MRI: Magnetic Resonance Imaging

SGOT: Serum Glutamic Oxaloacetic Transaminase

SGPT: Serum Glutamic Pyruvic Transaminase

SSFSE: Single Shot Fast Spin Echo

USG: Ultrasound 
Scientific Research Publishing (SCIRP) is one of the largest Open Access journal publishers. It is currently publishing more than 200 open access, online, peer-reviewed journals covering a wide range of academic disciplines. SCIRP serves the worldwide academic communities and contributes to the progress and application of science with its publication.

Other selected journals from SCIRP are listed as below. Submit your manuscript to us via either submit@scirp.org or Online Submission Portal.
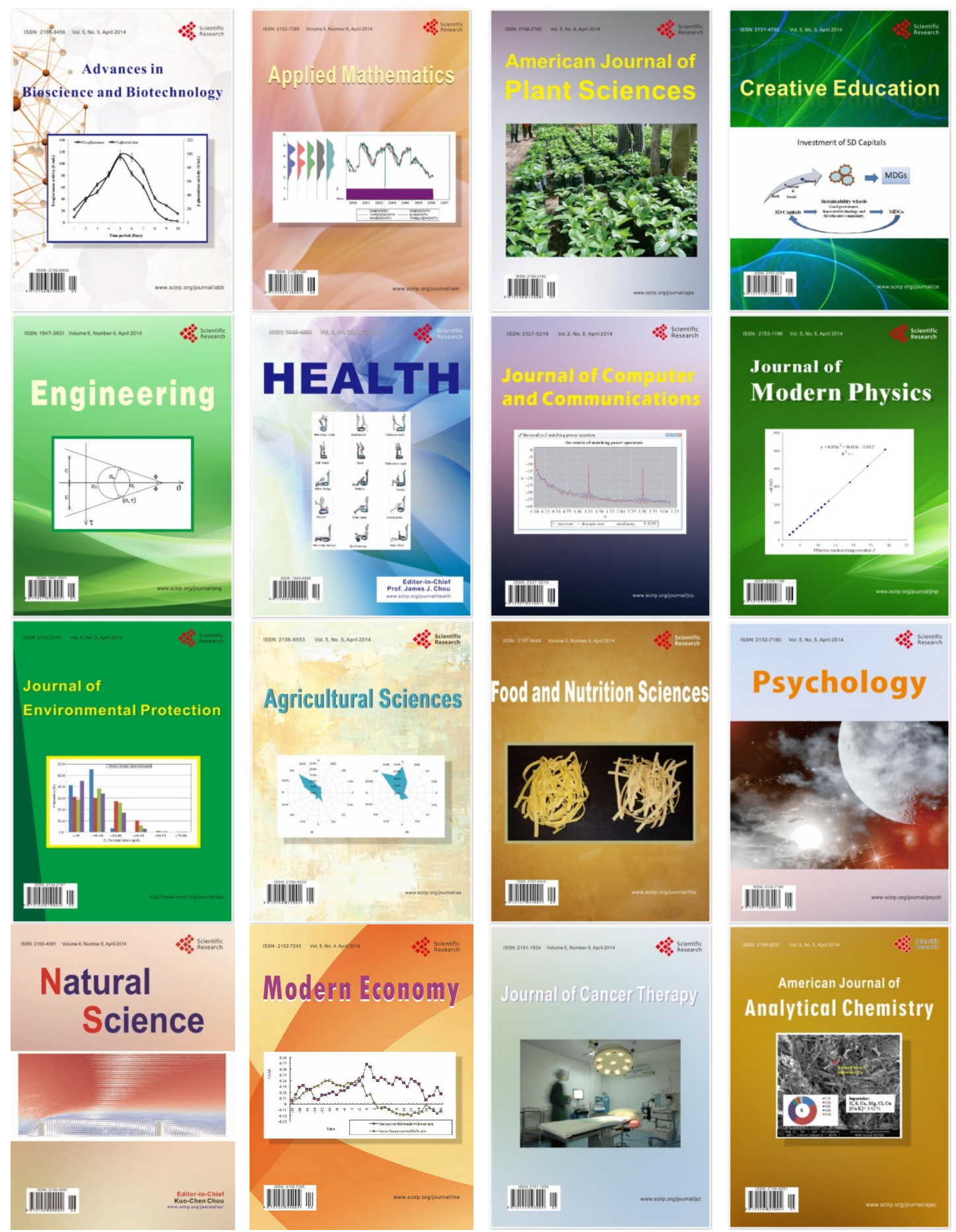